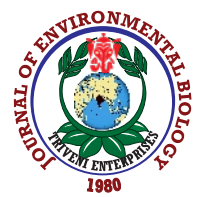

\title{
Adsorptive removal of dairy industrial pollutants by chitosan zinc-oxide nanoadsorbent- A comparitive study of artificial neural network and quadratic Box- Behnken design
}

\author{
B.L. Dinesha ${ }^{1 *}$, S. Hiregoudar', U. Nidoni ${ }^{2}$, K.T. Ramappa ${ }^{2}$, A.T. Dandekar ${ }^{3}$, M.V. Ravi ${ }^{4}$ and K.B. Sankalpa ${ }^{5}$ \\ ${ }^{1}$ Centre for Nanotechnology, College of Agricultural Engineering, University of Agricultural Sciences, Raichur- 584 101, India \\ ${ }^{2}$ Department of Processing and Food Engineering, College of Agricultural Engineering, University of Agricultural Sciences, Raichur- 584 101, India \\ ${ }^{3}$ Department of Agricultural Engineering, College of Agriculture, University of Agricultural Sciences, Mandya-571 405, India \\ ${ }^{4}$ Department of Soil Science and Agricultural Chemistry, College of Agriculture University of Agricultural Sciences, Raichur-584 101, India \\ ${ }^{5}$ Department of Agricultural Engineering, College of Horticulture, Kerala Agricultural University, Thrissur- 680656 , India
}

*Corresponding Author Email : dinirbdgtc@gmail.com

\section{Abstract}

Aim: To investigate the effect of operational parameters on the adsorption of biological oxygen demand (BOD) and chemical oxygen demand (COD) on to Chitosan zinc oxide $(\mathrm{CZnO})$ nanoadsorbent using cost-effective and eco-friendly nanoadsorbent based effluent treatment processes.

Methodology: CZnO nanoadsorbent particle was synthesized using chemical precipitation method. The nano size $<100 \mathrm{~nm}$ was achieved using high-speed cryo all mill, followed by the characterization using high-end instruments such as scanning electron microscope with elemental detection sensor (SEM-EDS), atomic force microscope (AFM), X-ray diffractometer (XRD) and Fourier transform inform infrared spectroscopy (FT-IR). Modeling and

$\mathrm{BBD}$

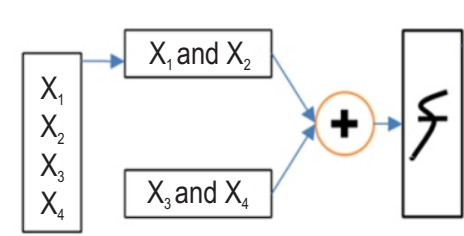

Variables

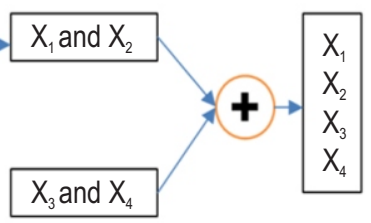

ANN Variables

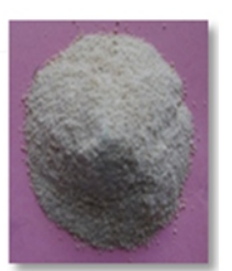

Synthesized $\mathrm{CZnO}$ optimization of operational parameters were done with the artificial neural network (ANN) and Box-BehnkenDesign (BBD) statistical tools.

Results: Optimized treatment combination for adsorption of BOD and COD were found at initial BOD and COD concentration of 100 and $200 \mathrm{mg} \mathrm{l}^{-1}$, $\mathrm{pH}$ of 7.0 and 2.0, adsorbent dosage of $1.25 \mathrm{mg} \mathrm{l}^{-1}$, contact time of 100 and $60 \mathrm{~min}$. In these conditionsthe desirability values of 0.988 and 0.950 were found for $\mathrm{BOD}$ and COD adsorption. The maximum per cent reduction of BOD and COD by using CZnO nanoadsorbent was found to be 96.71 and 87.56 . Two models such as Quadratic Box-Behnken and ANN were compared in term of sum of square errors (SSE), root mean square error (RMSE) and correlation coefficient $\left(R^{2}\right)$ values.

Interpretation: The results obtained revel the well trained ANN model found to be more accurate in prediction of BOD and COD adsorption process parameters compared to BBD model.

Key words: Biological oxygen demand, Chemical oxygen demand, Dairy industry, Nanotechnology, Wastewater treatment

How to cite : Dinesha, B.L., S. Hiregoudar, U. Nidoni, K.T. Ramappa, A.T. Dandekar, M.V. Ravi and K.B. Sankalpa: Adsorptive removal of dairy industrial pollutants by chitosan zinc-oxide nanoadsorbent- A comparitive study of artificial neural network and quadratic Box-Behnken design. J. Environ. Biol., 42, 1442-1451 (2021). 


\section{Introduction}

Ever increasing industrialization and rapid urbanization have considerably increased the rate of water pollution worldwide. Among various kinds of industries in India, diary industry (DI) is of crucial importance and contributes $35 \%$ of the total Asian milk (Thirugnanasambandham and Ganesamoorthy, 2019). Wastewater released from the DI contain high amount of total dissolved solids, total suspended solids, $\mathrm{pH}$, electrical conductivity, turbidity, biological oxygen demand, chemical oxygen demand, phosphate, sulphate, nitrate-nitrogen, ammoniacal-nitrogen, chloride, oil and grease (Dinesha et al., 2021a).

To defend the non-toxic global water inventory, the various environmental regulations and emission standards have been represented to address pollution issues. To meet the wastewater discharge limits set by the state as well as central pollution control boards, the $\mathrm{DI}$ are following various treatment methods (biological and physicochemical) before discharging in to the enviornoment (Qasim and Mane, 2013).

Biological treatment methods can be generally classified as aerobic and anaerobic treatments. A common aerobic method such as activated sludge process is performed by allowing wastewater flow into the aerated tank and agitating the sludge. Trickling filters, rotating biological contactor process, and biotowers have also been employed for the treatment of wastewater. Anaerobic treatment composes processes that occur in an environment devoid of air or elemental oxygen (Thirugnanasambandham et al., 2014). However, the performance of the biological treatment process is low due to the high organic load and the toxic nature of the dairy industry wastewater (DIWW). The traditional physicochemical treatment processes have accomplished to some extent. Hence, secondary pollution occurs due to low BOD and COD reduction in existing dairy industrial effluent treatment plants (Thirugnanasambandham and Sivakumar, 2015).

Some of the major important traditional methods of wastewater treatment process are preliminary treatment, which is used for removal of large solids such as rags, sticks, grit and grease (Arora et al., 2005). Primary treatments are used for the removal of floating and settleable materials such as, suspended solids and organic matter (Bora and Dutta, 2014). Secondary treatment includes both biological (aerobic and anaerobic treatments) and chemical methods (Ferric chloride, Aluminum chloride, Aluminum sulfate and Ferric chloride) to remove biodegradable organic matter and suspended solids (Stoller et al., 2016). Tertiary or advanced treatments methods are used for the removal of residual suspended solids or dissolved solids by using membrane techniques (micro and ultrafiltration) (Routh et al., 2016), reverse osmosis, ozone technology (Pandiselvam et al., 2020), electro-coagulation (Qasim and Mane, 2013) and activated sludge treatment (Teh et al., 2014). Some of the promising wastewater treatment techniques or tools introduced by nanotechnology are photocatalysis (Oladipo et al., 2017), nanomembranes (Dinesha et al., 2017) and nanoadsorbents (Thirugnanasambandham and Ganesamoorthy, 2019).'

Generally, BOD and COD adsorption approaches include the traditional and novel adsorption methods. Among these methods, novel physico-chemical methods (adsorption, photocatalysis, ozone technology and ion exchage) are generally in usage due to eco-friendly, highest reduction capacity of the pollutants, low cost and operators friendly (Pathak et al., 2016). In this contest, to meet the global environmental sustainability the synthesis and characterization of novel adsorbents with high adsorption capacity and high rate gives more commertial importance (Dinesha et al., 2021a). Previous studies reported that, metal oxide based materials were highly efficient adsorbents for adsorption of organic pollutants (Raut et al., 2016). Recently, metal oxide based nanoparticles gained demand in environmental and biological engineering due to their charming intrinsic properties (Thirumavalavan et al., 2013). The development of an eco-friendly and energy-efficient approach at larger scale is still a challenge (Maran et al., 2013).

Performance of the adsorption process at an insignificant state could be more reagent consumption and it may take more time. Hence, process optimization for adsorption of BOD and COD is very much important (Dinesha et al., 2021a). One factor at a time (OFAT), response surface methodology (RSM) and the artificial neural network (ANN) modeling approaches are generally used for optimization (Dinesha et al., 2021b). Generally ANN and RSM were used for adsorption process optimization and standardization in the field of wastewater treatment. There are several disadvantages in the OFAT method, such as operational parameters between interaction effects were not considered for optimization and not used for validation (Pandiselvam et al., 2020). In views of this, present study mainly aimed to optimize the process technology for per cent reduction of $\mathrm{BOD}$ and $\mathrm{COD}$ from DIWW using $\mathrm{CZnO}$ nanoadsorbent with BBD and ANN models.

\section{Materials and Methods}

Chemical reagents required for the synthesis of nanoadsorbents were purchased from M/s. Sigma Aldrich Chemicals, Bengaluru, India. BOD and COD were estimated according to the method described by AOAC (2006) (Method 973.44 and 973.46). Synthesized nanoparticles were characterized by using Scanning electron microscope with Elemental detection sensor (SEM-EDS), Atomic force microscope (AFM), X-ray diffractometer (XRD) and Fourier transform inform infrared spectroscopy (FT-IR).

Synthesis of CZnO nanoadsorbent: $\mathrm{CZnO}$ nanoadsorbent was synthesized as per the method described by Thirugnanasambambandham and Sivakumar (2015).

Batch adsorption experiment: Batch adsorption study for per 
cent reduction of $\mathrm{BOD}\left(\% \mathrm{R}_{\mathrm{BO}}\right)$ and percent reduction of $\mathrm{COD}$ $\left(\% \mathrm{R}_{\text {coo }}\right)$ by using $\mathrm{CZnO}$ nanoadsorbent was performed according to the method described by Thirugnanasambandham et al. (2014). The value of per cent reduction of BOD and COD were calculated by the following equation:

$$
\text { Per cent reduction }=\left[\frac{\mathrm{C}_{0}{ }^{-} \mathrm{C}_{\mathrm{e}}}{\mathrm{C}_{0}}\right] \times 100
$$

Where, $C_{0}$ and $C_{\theta}$ are initial and final concentration of $B O D$

Box-Behnken Design: The input variables varied at different levels to observe their effect on per cent reduction of $B O D$ and $\mathrm{COD}$ by using $\mathrm{CZnO}$ nanoadsorbent. The obtained results of the experimental design matrix were performed by using BBD. The quadratic model of RSM and experimental data obtained by using BBD were used to train ANN by using feed forward back propagation neural network (Yadav et al., 2018). BBD matrix of experimental data sets and their observed responses were tabulated. Design Expert software (8.0.7.1 trial version) was used for BBD modeling. Independent variables and their levels were selected for $\% R_{\text {BоD }}$ and $\% R_{\text {соD }}$ by using $\mathrm{CZnO}$ nanoadsorbent (Table 1).

Artificial Neural Network: ANN was applied for the simulation of experimental data of batch adsorption study by using MATLAB Subroutine Prepca-007 software (Karimi et al., 2012). Twentynine patterns were used for ANN modeling. Two components viz., $\operatorname{BOD}\left(Y_{1}\right)$ and $\operatorname{COD}\left(Y_{2}\right)$ were used for training, cross-validation and testing the neural networks. Four components viz., initial concentration $\left(X_{1}\right)$, dosage $\left(X_{2}\right)$, pH $\left(X_{3}\right)$ and contact time $\left(X_{4}\right)$ were used for input variables. The training process was run until the Sum of Square Errors (SSE) reached minimum values in the validation process. The performance of the trained network was estimated based on the accuracy of network with the test data. A feed-forward multilayered perceptron (MLP) was used for network training. Back-propagation (BP) algorithm was selected to develop the predicted model because of its reported ability to model any function. ANN parameters were adjusted by using the number of hidden layers, neurons, type of transfer function, learning rate, momentum and number of patterns. A hyperbolic tangent sigmoid transfer function was used to activate neurons (Youssefi et al., 2013).

Comparison of RSM and ANN models: Both well trained RSM and ANN models were compared in terms of sums of square error (SSE), root mean square error (RMSE), correlation coefficient $\left(R^{2}\right)$ and adjusted $R^{2}$ values. These were

Table 1: Independent variables and their levels for per cent reduction of $\mathrm{BOD}$ and $\mathrm{COD}$ by $\mathrm{CZnO}$ nanoadsorbent

\begin{tabular}{|c|c|c|c|c|c|}
\hline \multirow[b]{2}{*}{ Variables } & \multirow[b]{2}{*}{ Unit } & \multirow[b]{2}{*}{ Factors } & \multicolumn{3}{|l|}{ Levels } \\
\hline & & & Low (-1) & Middle (0) & High (+1) \\
\hline \multirow[t]{2}{*}{ Initial concentration } & $\mathrm{mg} \mathrm{l}^{-1}$ & $X_{1 \text { (BOD) }}$ & 100 & 200 & 300 \\
\hline & & $X_{1 \text { (COD) }}$ & 200 & 400 & 600 \\
\hline $\mathrm{pH}$ & & $\mathrm{X}_{2}$ & 2 & 7 & 12 \\
\hline Dosage & $\mathrm{mg}^{-1}$ & $X_{3}$ & 0.5 & 1.25 & 2 \\
\hline Contact time & $\min$ & $X_{4}$ & 20 & 60 & 100 \\
\hline
\end{tabular}

Table 2: Results ofANOVAfor the Response Surface Quadratic model

\begin{tabular}{|c|c|c|c|c|c|c|}
\hline \multirow{3}{*}{$\begin{array}{l}\text { Source of } \\
\text { variation }\end{array}$} & \multicolumn{6}{|c|}{ CZnO nanoadsorbent } \\
\hline & \multicolumn{3}{|c|}{$\mathrm{R} \%_{\mathrm{BOD}}$} & \multicolumn{3}{|c|}{$\mathrm{R} \%_{\mathrm{COD}}$} \\
\hline & Sum of squares & $F$ value & $\mathrm{p}$-value Prob $>\mathrm{F}$ & Sum of squares & F value & $p$-value Prob $>F$ \\
\hline Model & 6047.46 & 80.55 & $<0.0001$ & 8246.62 & 17.25 & $<0.0001$ \\
\hline$X_{1}$ & 5955 & 1110.51 & $<0.0001$ & 2824.71 & 82.7 & $<0.0001$ \\
\hline $\mathrm{X}_{2}$ & 5.94 & 1.11 & 0.003 & 41.66 & 1.22 & 0.002 \\
\hline$X_{3}$ & 6.24 & 1.16 & 0.002 & 3.21 & 0.09 & 0.007 \\
\hline$X_{4}$ & 47.01 & 8.77 & 0.001 & 237.1 & 6.94 & 0.001 \\
\hline$X_{1} X_{2}$ & 0.42 & 0.08 & 0.007 & 0.23 & 0.01 & 0.009 \\
\hline$X_{1} X_{3}$ & 3.5 & 0.65 & 0.004 & 4.54 & 0.13 & 0.007 \\
\hline$X_{1} X_{4}$ & 4.58 & 0.85 & 0.003 & 106.81 & 3.13 & 0.009 \\
\hline $\mathrm{X}_{2} \mathrm{X}_{3}$ & 0.47 & 0.09 & 0.007 & 1.16 & 0.03 & 0.008 \\
\hline $\mathrm{X}_{2} \mathrm{X}_{4}$ & 0.09 & 0.02 & 0.008 & 0.65 & 0.02 & 0.008 \\
\hline$X_{3} X_{4}$ & 0.96 & 0.18 & 0.006 & 15.29 & 0.45 & 0.005 \\
\hline Residual & 75.07 & & & 478.17 & & \\
\hline Lack of Fit & 75.07 & 11039.8 & $<0.0001$ & 478.17 & 125833 & $<0.0001$ \\
\hline
\end{tabular}


carried out between experimental and predicted data as depicted in Eqn. (4) to (6). To study the modeling abilities of RSM and ANN, the values predicted by RSM and ANN models were plotted against the corresponding experimental values
(Srikanth et al., 2020). Value of correlation coefficient measures the scattering predicted data around the straight line (1:1). $R^{2}$ value closed to 1.0 indicates that the model is good fit (Jha etal., 2017).

Table 3: Verification of predicted and actual responses of per cent reduction of BOD and COD by using CZnO nanoadsorbent

\begin{tabular}{|c|c|c|c|c|c|c|c|c|c|}
\hline & Pollutants & $\begin{array}{l}\text { Nano } \\
\text { adsorbents }\end{array}$ & $\begin{array}{l}\text { Initial } \\
\text { concentration } \\
\left(\mathrm{mg} \mathrm{l}^{-1}\right)\end{array}$ & $\mathrm{pH}$ & $\begin{array}{l}\text { Dosage } \\
\left(\mathrm{mg} \mathrm{l}^{-1}\right)\end{array}$ & $\begin{array}{l}\text { Contact } \\
\text { time (min) }\end{array}$ & $\%$ Reduction & Desirability & R-Squared \\
\hline Predicted & & & 100 & 7 & 1.25 & 100 & 96.84 & & \\
\hline Experimental & BOD & $\mathrm{CZnO}$ & 100 & 7 & 1.25 & 100 & 96.71 & 0.981 & 0.988 \\
\hline $\begin{array}{l}\% \text { Relative } \\
\text { deviation (\%RD) }\end{array}$ & & & - & - & - & - & -0.004 & & \\
\hline Predicted & & & 200 & 2 & 1.25 & 60 & 87.55 & & \\
\hline Experimental & COD & $\mathrm{CZnO}$ & 200 & 2 & 1.25 & 60 & 87.56 & 0.986 & 0.950 \\
\hline $\begin{array}{l}\% \text { Relative } \\
\text { deviation (\%RD) }\end{array}$ & & & - & - & - & - & 0.0003 & & \\
\hline
\end{tabular}

Table 4: Coded and un-coded Box-Behnken design of independent variables and their corresponding experimental and predicted values

\begin{tabular}{|c|c|c|c|c|c|c|c|c|c|c|c|}
\hline \multirow{2}{*}{ Run } & \multicolumn{2}{|c|}{$X_{1}\left(\mathrm{mg} \mathrm{l}^{-1}\right)$} & \multirow[t]{2}{*}{$X_{2}$} & \multirow{2}{*}{$\begin{array}{l}X_{3} \\
\left(\mathrm{mg} \mathrm{l}^{-1}\right)\end{array}$} & \multirow[t]{2}{*}{$X_{4}(\min )$} & \multicolumn{3}{|c|}{$\begin{array}{r}\mathrm{R} \%_{\text {воD }} \text { in } \mathrm{CZnO} \\
\text { nanoadsorbent }\end{array}$} & \multicolumn{3}{|c|}{$\begin{array}{l}\mathrm{R} \%_{\operatorname{coo}} \text { in } \mathrm{CZnO} \\
\text { nanoadsorbent }\end{array}$} \\
\hline & BOD & COD & & & & $Y_{\text {EXP }}$ & $Y_{\mathrm{RSM}}$ & $Y_{\text {ANN }}$ & $Y_{\text {EXP }}$ & $Y_{\mathrm{RSM}}$ & $\mathbf{Y}_{\mathrm{ANN}}$ \\
\hline 1 & $100(-1)$ & $200(-1)$ & $2(-1)$ & $1.25(0)$ & $60(0)$ & 95.12 & 93.84 & 95.15 & 87.56 & 82.05 & 87.54 \\
\hline 2 & $300(+1)$ & $600(+1)$ & $2(-1)$ & $1.25(0)$ & $60(0)$ & 51.4 & 48.64 & 51.72 & 60.08 & 51.85 & 60.04 \\
\hline 3 & $100(-1)$ & $200(-1)$ & $12(+1)$ & $1.25(0)$ & $60(0)$ & 92.5 & 91.79 & 93.03 & 82.35 & 78.81 & 82.33 \\
\hline 4 & $300(+1)$ & $600(+1)$ & $12(+1)$ & $1.25(0)$ & $60(0)$ & 50.08 & 47.88 & 50.67 & 53.91 & 47.65 & 53.87 \\
\hline 5 & $200(0)$ & $400(0)$ & $7(0)$ & $0.5(-1)$ & $20(-1)$ & 70.06 & 66.62 & 69.75 & 39.75 & 35.51 & 39.76 \\
\hline 6 & $200(0)$ & $400(0)$ & $7(0)$ & $2(+1)$ & $20(-1)$ & 72.51 & 69.04 & 71.98 & 43.64 & 40.45 & 43.64 \\
\hline 7 & $200(0)$ & $400(0)$ & $7(0)$ & $0.5(-1)$ & $100(+1)$ & 71.56 & 71.56 & 72 & 56.89 & 48.31 & 56.91 \\
\hline 8 & $200(0)$ & $400(0)$ & $7(0)$ & $2(+1)$ & $100(+1)$ & 72.05 & 72.02 & 71.85 & 52.96 & 45.43 & 52.95 \\
\hline 9 & $100(-1)$ & $200(-1)$ & $7(0)$ & $1.25(0)$ & $20(-1)$ & 90.57 & 91 & 90.36 & 82.05 & 84.57 & 82.04 \\
\hline 10 & $300(+1)$ & $600(+1)$ & $7(0)$ & $1.25(0)$ & $20(-1)$ & 47.68 & 48.59 & 47.08 & 40.18 & 43.56 & 40.12 \\
\hline 11 & $100(-1)$ & $200(-1)$ & $7(0)$ & $1.25(0)$ & $100(+1)$ & 96.71 & 97.1 & 96.38 & 80.3 & 83.12 & 80.26 \\
\hline 12 & $300(+1)$ & $600(+1)$ & $7(0)$ & $1.25(0)$ & $100(+1)$ & 49.54 & 50.41 & 49.53 & 59.1 & 62.78 & 59.11 \\
\hline 13 & $200(0)$ & $400(0)$ & $2(-1)$ & $0.5(-1)$ & $60(0)$ & 69.42 & 68.89 & 69.04 & 35.84 & 40.89 & 35.82 \\
\hline 14 & $200(0)$ & $400(0)$ & $12(+1)$ & $0.5(-1)$ & $60(0)$ & 67.29 & 66.8 & 67.89 & 32.58 & 36.09 & 32.59 \\
\hline 15 & $200(0)$ & $400(0)$ & $2(-1)$ & $2(+1)$ & $60(0)$ & 67.86 & 69.65 & 67.91 & 38.16 & 40.85 & 38.19 \\
\hline 16 & $200(0)$ & $400(0)$ & $12(+1)$ & $2(+1)$ & $60(0)$ & 67.1 & 68.93 & 67.63 & 37.05 & 38.2 & 37.05 \\
\hline 17 & $100(-1)$ & $200(-1)$ & $7(0)$ & $0.5(-1)$ & $60(0)$ & 89.45 & 91.18 & 89.41 & 80.45 & 81.65 & 80.44 \\
\hline 18 & $300(+1)$ & $600(+1)$ & $7(0)$ & $0.5(-1)$ & $60(0)$ & 45.76 & 48.49 & 45.27 & 45.76 & 48.85 & 45.74 \\
\hline 19 & $100(-1)$ & $200(-1)$ & $7(0)$ & $2(+1)$ & $60(0)$ & 95.05 & 94.49 & 95.15 & 78.05 & 80.56 & 78.04 \\
\hline 20 & $300(+1)$ & $600(+1)$ & $7(0)$ & $2(+1)$ & $60(0)$ & 47.62 & 48.07 & 47.49 & 47.62 & 52.01 & 47.54 \\
\hline 21 & $200(0)$ & $400(0)$ & $2(-1)$ & $1.25(0)$ & $20(-1)$ & 65.58 & 68.67 & 65.56 & 38.58 & 39.57 & 38.57 \\
\hline 22 & $200(0)$ & $400(0)$ & $12(+1)$ & $1.25(0)$ & $20(-1)$ & 64.47 & 66.95 & 64.51 & 34.47 & 35.04 & 34.45 \\
\hline 23 & $200(0)$ & $400(0)$ & $2(-1)$ & $1.25(0)$ & $100(+1)$ & 72.63 & 72.32 & 72.66 & 42.63 & 47.65 & 42.6 \\
\hline 24 & $200(0)$ & $400(0)$ & $12(+1)$ & $1.25(0)$ & $100(+1)$ & 72.13 & 71.22 & 71.17 & 40.13 & 44.73 & 40.15 \\
\hline 25 & $200(0)$ & $400(0)$ & $7(0)$ & $1.25(0)$ & $60(0)$ & 69.86 & 69.85 & 69.84 & 37.56 & 37.53 & 37.54 \\
\hline 26 & $200(0)$ & $400(0)$ & $7(0)$ & $1.25(0)$ & $60(0)$ & 69.88 & 69.85 & 69.87 & 37.52 & 37.53 & 37.51 \\
\hline 27 & $200(0)$ & $400(0)$ & $7(0)$ & $1.25(0)$ & $60(0)$ & 69.82 & 69.85 & 69.82 & 37.51 & 37.53 & 37.5 \\
\hline 28 & $200(0)$ & $400(0)$ & $7(0)$ & $1.25(0)$ & $60(0)$ & 69.82 & 69.85 & 69.83 & 37.52 & 37.53 & 37.53 \\
\hline 29 & $200(0)$ & $400(0)$ & $7(0)$ & $1.25(0)$ & $60(0)$ & 69.85 & 69.85 & 69.85 & 37.52 & 37.53 & 37.5 \\
\hline
\end{tabular}

$X_{1}$ - Initial BOD concentration $\left(\mathrm{mgl}^{-1}\right) ; X_{2}-\mathrm{pH} ; X_{3}-\mathrm{CZnO}$ dosage $\left(\mathrm{mgl}^{-1}\right) ; X_{4}-$ Contact time $(\mathrm{min}) ; Y_{\text {EXP }}-$ Experimental value; $Y_{\text {RSM }}-$ Predicted by RSM model; $Y_{A N N}-$ Predicted by ANN model. 


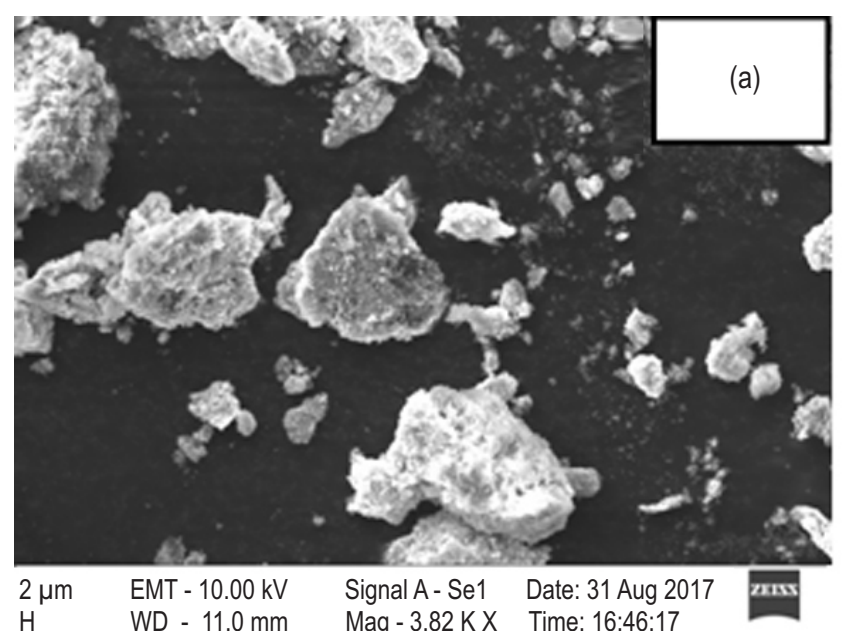

$\mathrm{H} \quad$ WD $-11.0 \mathrm{~mm} \quad$ Mag-3.82 KX Time: 16:46:17

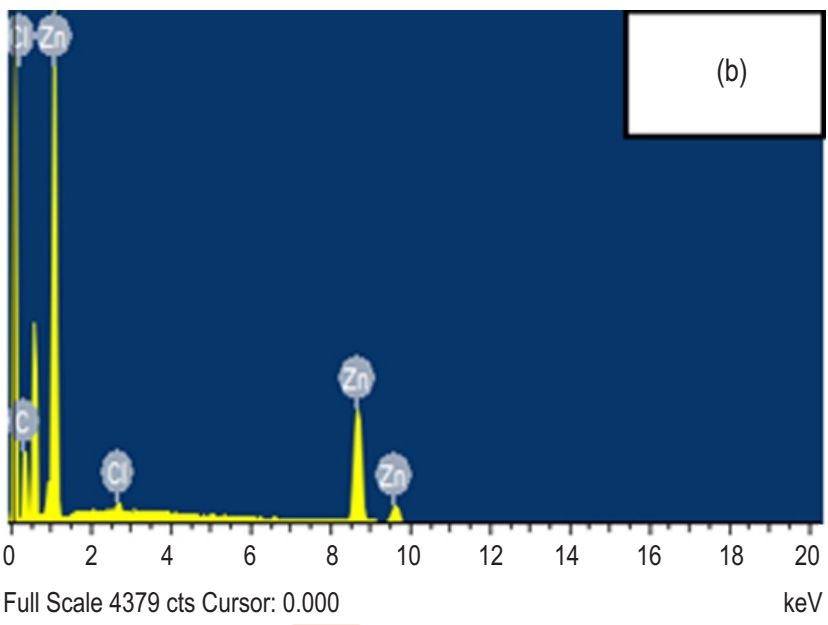

Full Scale 4379 cts Cursor: 0.000

Fig. 1: SEM image (a) and EDS spectrum; (b) of CZnO nanoadsorbent (88.35 d.nm).

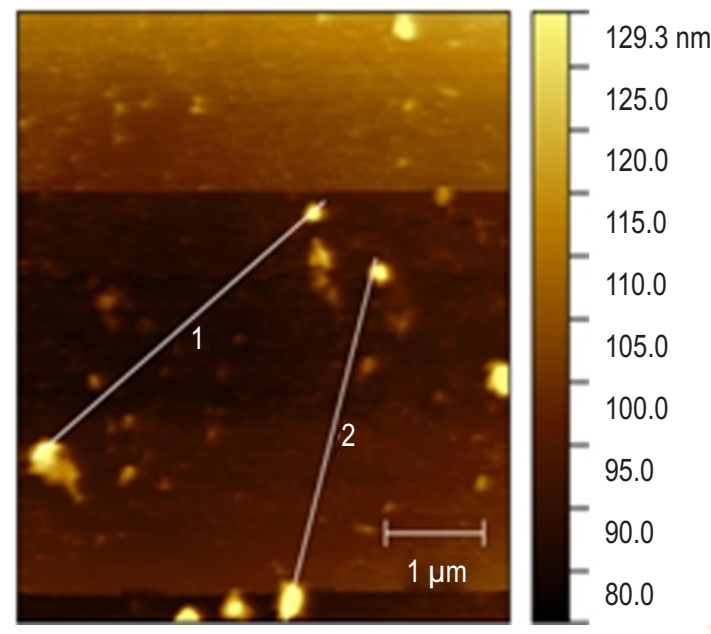

Fig. 2: Profile image obtained by using AFM for $\mathrm{CZnO}$ nanoadsorbent.

\section{Results and Discussion}

Average particle size and Zeta potential of synthesized $\mathrm{CZnO}$ nanoadsorbent was found to be $88.35 \mathrm{~d}$. $\mathrm{nm}$ and $-23.70 \mathrm{mV}$. SEM image (Fig. 1a) of synthesized CZnO nanoadsorbent showed rough surface and rod-like formations, which might be due to increased $\mathrm{NaOH}$ concentration during $\mathrm{CZnO}$ synthesis and increased the interaction between chitosan and $\mathrm{ZnO}$ (Preethi et al., 2020). EDS spectra (Fig. 1b) of CZnO showed the characteristic peaks of zinc $(59.98 \%)$, chlorine $(0.43 \%)$ and carbon (39.60\%). Topography image (Fig. 2) obtained by AFM for CZnO nanoadsorbent indicated the height (Y-axis) and width (X-axis) of the particles.

Surface roughness value of $6.75 \mathrm{~nm}$ was obtained due to the rough surface area of $\mathrm{CZnO}$ nanoadsorbent. Thin grooves on 3D image were due to the presence of $\mathrm{ZnO}$ as confirmed by the results of Wardana et al. (2020). A definite line broadening XRD peaks indicated that the material consisted of particles in nanoscale. Diffraction peaks (Fig. 3) of $\mathrm{CZnO}$ indicated the nanocrystalline nature, identical to the hexagonal phase with Wurtzite structure (Hamedani and Farzaneh, 2006). $\mathrm{CZnO}$ peaks at angle $(2 \theta)$ were found to have $19.80^{\circ}, 33.18^{\circ}$, $34.47^{\circ}, 36.29^{\circ}, 47.53^{\circ}, 48.38^{\circ}, 56.57^{\circ}, 62.86^{\circ}, 66.42^{\circ}, 67.95^{\circ}$ and $69.08^{\circ}$ corresponding to the reflection from $4.48^{\circ}, 2.81^{\circ}$, $2.69^{\circ}, 2.59^{\circ}, 2.47^{\circ}, 1.91^{\circ}, 1.87^{\circ}, 1.62^{\circ}, 1.47^{\circ}, 1.40^{\circ}, 1.37^{\circ}$ and $1.35^{\circ}$ crystal planes, respectively.

All these diffraction peaks are in good agreement with those of hexagonal wurtzite structure of $\mathrm{ZnO}$ (Preethi et al., 2020). FT-IR spectrum of CZnO nanoadsorbent (Fig. 4) showed bands at 3365.78 and $2881.65 \mathrm{~cm}^{-1}$ due to the stretching vibration mode of $\mathrm{NH}_{2}$ and $\mathrm{OH}$ groups. The peaks at 2428.38 and 1788.01 $\mathrm{cm}^{-1}$ were typically carboxylic acid $\mathrm{O}-\mathrm{H}$ stretching vibration, while the bands at 1647.21 and $1560.41 \mathrm{~cm}^{-1}$ were due to amide I group ( $\mathrm{N}-\mathrm{H}$ bend). The transmission peak at $1340.53 \mathrm{~cm}^{-1}$ was attributed to $\mathrm{C}-\mathrm{H}$ deformation. The special broad peaks at 1151.50 and $1026.13 \mathrm{~cm}^{-1}$ were attributed to the vibration mode of alkoxy C-O (Oladipo et al., 2017). Lack of fit test and model summary statistics for linear, $2 \mathrm{FI}$, quadratic and cubic models for the adsorption of BOD and COD into $\mathrm{CZnO}$ nanoadsorbent was performed.

According to the significant lack of fit test, R-squared, adjusted R-squared and the predicted R-squared values of quadratic model was performed for two responses $\left(\% \mathrm{R}_{\mathrm{BOD}}\right.$ and $\% R_{\text {coo }}$ ). A quadratic model was selected for the analysis of responses. ANOVA (Table 2) for the quadratic model was applied to test the statistical significant factors. ANOVA for adsorption of $\mathrm{BOD}$ and $\mathrm{COD}$ into $\mathrm{CZnO}$ nanoadsorbent was shown good model F-values of 80.55 and 17.25 , respectively. Lower P-values of $(<0.0001)$ quadratic model conformed well applicability for 


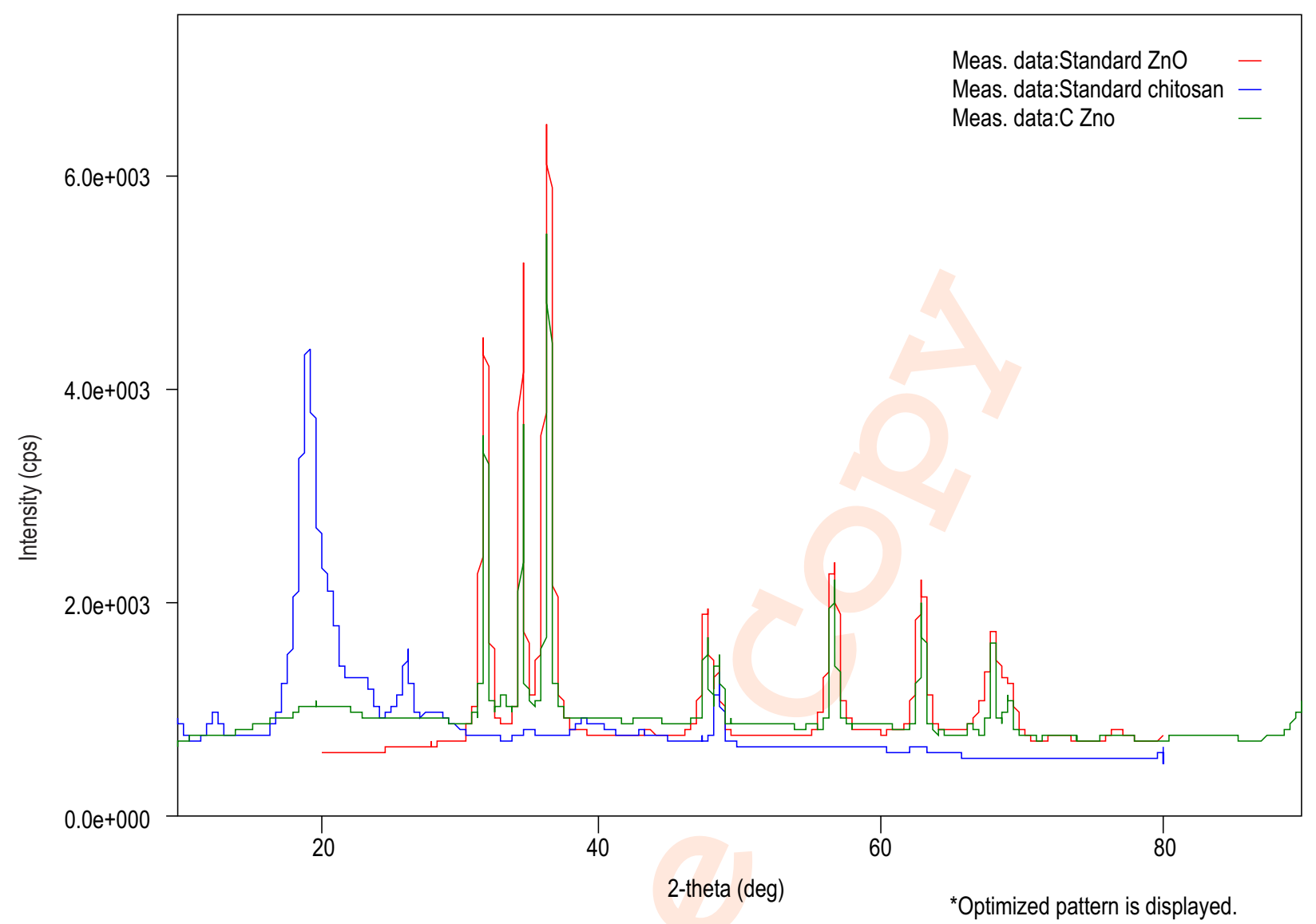

Fig. 3: Diffractogram of standard $\mathrm{ZnO}$, chitosan and synthesized $\mathrm{CZnO}$ nanoadsorbent.

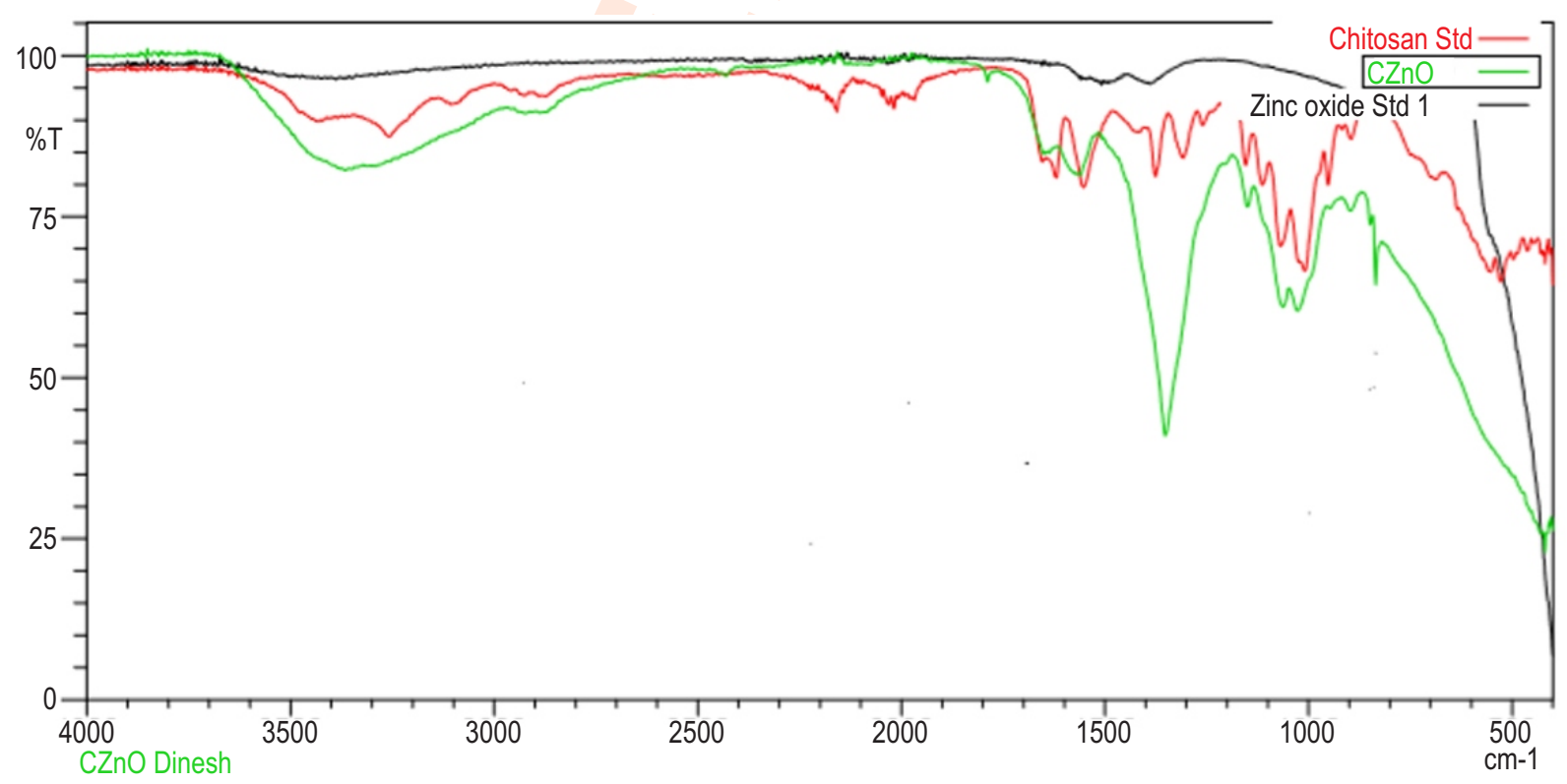

Fig. 4: FT-IR spectrum of standard ZnO, chitosan and synthesized CZnO nanoadsorbent. 
(a)

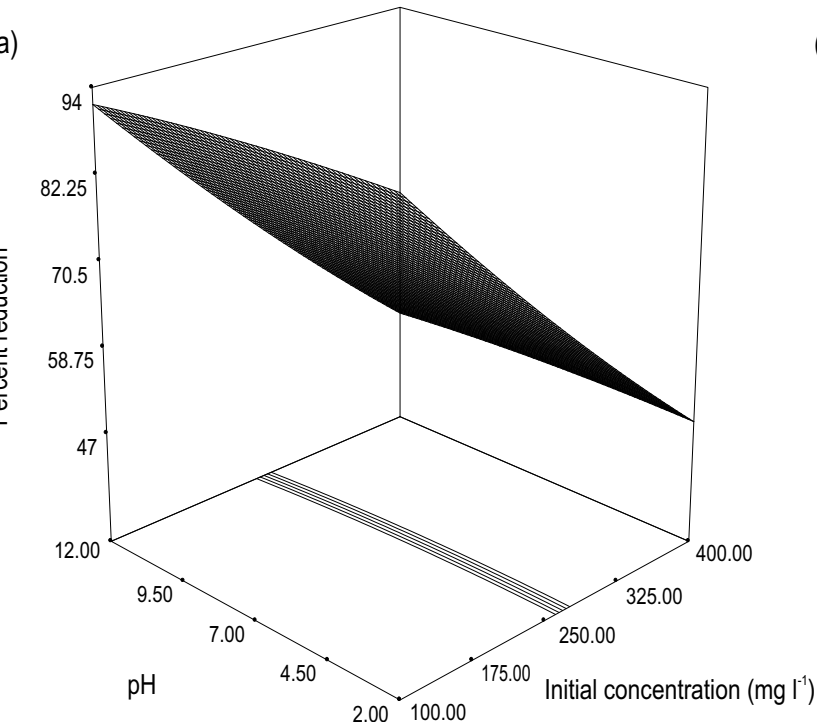

(b)

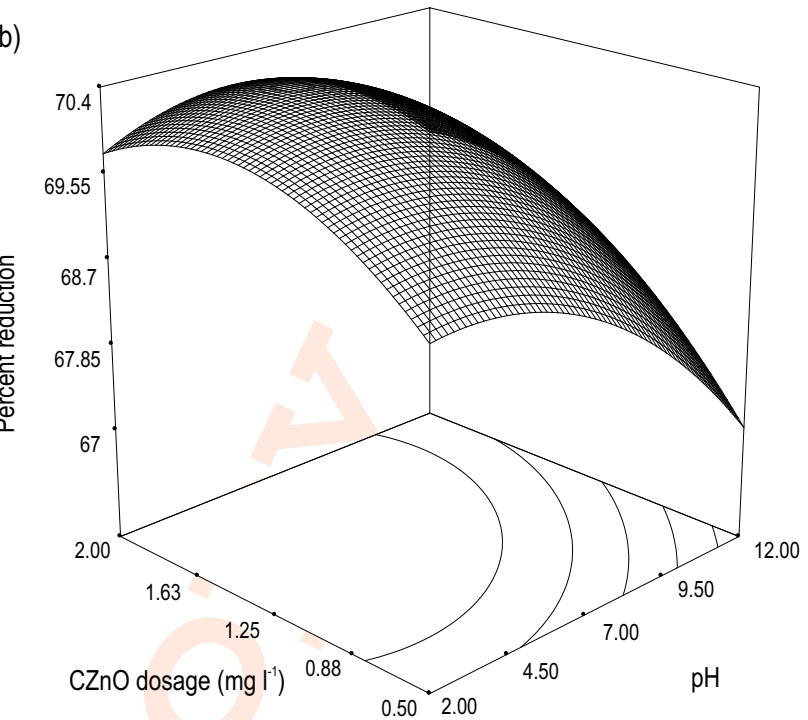

(c)

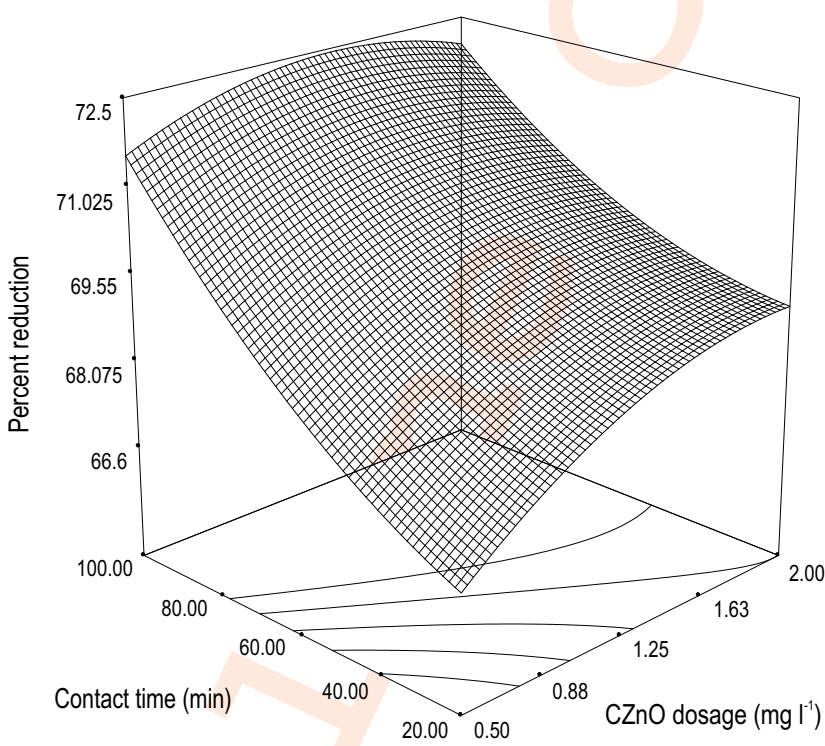

Fig. 5: Response surface plots for per cent reduction of $\mathrm{BOD}$ using $\mathrm{CZnO}$ nanoadsorbent as a function of (a) $\mathrm{pH}$ and initial concentration; (b) Dosage and $\mathrm{pH}$ and (c) Contact time and dosage.

correlating the adsorption of $\mathrm{BOD}$ and $\mathrm{COD}$ into $\mathrm{CZnO}$ nanoadsorbent. Similarly, the Lack of Fit F-values for adsorption $\mathrm{BOD}$ and $\mathrm{COD}$ into $\mathrm{CZnO}$ were obtained to be 11039.84 and 125833 , respectively. The final equations obtained in terms of actual factors are given as following equations (Eqn. 2-3):

$\mathrm{R} \%_{\text {ВоD }}$ in presence of $\mathrm{CZnO}=69.85-22.28{ }^{*} \mathrm{X}_{1}$ $0.70 * X_{2}+0.72 * X_{3}+1.98 * X_{4}+0.33 * X_{1}^{*} X_{2}-0.93 * X_{1}{ }^{*} X_{3}-$ $1.07^{*} X_{1}^{*} X_{4}+0.34^{*} X_{2}^{*} X_{3}+0.15^{*} X_{2}^{*} X_{4}-0.49 * X_{3}^{*} X_{4}+1.34{ }^{*} X_{1}^{2}-$ $0.65^{*} X_{2}^{2}-0.63^{*} X_{3}^{2}+0.59^{*} X_{4}^{2}$
$\mathrm{R} \%_{\text {COD }}$ in presence of $\mathrm{CZnO}=37.53-15.34{ }^{*} \mathrm{X}_{1}$ $1.86{ }^{*} X_{2}+0.52 * X_{3}+4.45^{*} X_{4}-0.24{ }^{*} X_{1}{ }^{*} X_{2}+1.07 * X_{1}{ }^{*} X_{3}+$ $5.17{ }^{*} X_{1}{ }^{*} X_{4}+0.54{ }^{*} X_{2}{ }^{*} X_{3}+0.40 * X_{2}{ }^{*} X_{4}-1.96 * X_{3}{ }^{*} X_{4}+$ $27.16^{*} X_{1}^{2}+0.40^{*} X_{2}^{2}+1.08^{*} X_{3}^{2}+3.82^{*} X_{4}^{2}$

In the adsorption process, to obtain the best condition the responses are maximized. Therefore, the desirability function approach under BBD was used as goal by choice of value from 0.0 (unacceptable) to 1.0 (acceptable). Verification of predicted and 

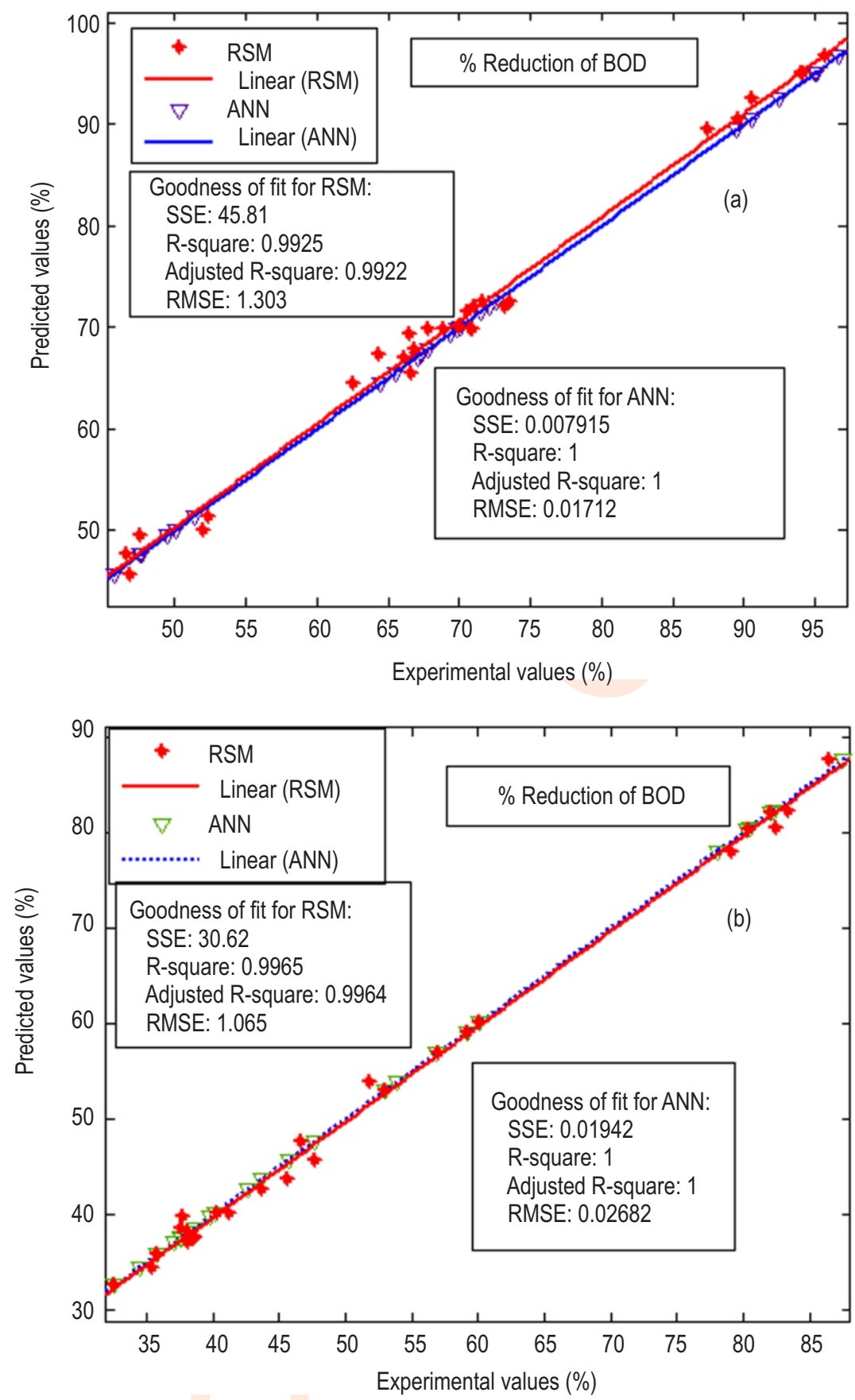

Fig. 6: Comparison of experimental with predicted values of RSM and ANN models plot (a) $\% R_{B 0 D}$ in presence of CZnO nanoadsorbent and (b) \% $R_{\text {coD }}$ in presence of $\mathrm{CZnO}$ nanoadsorbent.

actual responses is depicted in Table 3. The optimized treatment combination for $\% \mathrm{R}_{\mathrm{BOD}}$ using $\mathrm{CZnO}$ nanoadsorbent was found at initial concentration of $100 \mathrm{mg} \mathrm{l}^{-1}$, $\mathrm{pH} 7$, dosage of $1.25 \mathrm{mg} \mathrm{I}^{-1}$ and contact time of $100 \mathrm{~min}$. This optimized treatment combination resulted, the per cent relative deviation $(\% \mathrm{RD})$ values of -0.004 , desirability values of 0.981 and R-squared values of 0.988 .
Similarly, the optimized treatment combination for $\% \mathrm{R}_{\text {COD }}$ using $\mathrm{CZnO}$ nanoadsorbent was found at an initial concentration of

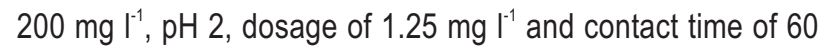
min. This optimized treatment combination resulted, the per cent relative deviation (\%RD) values of 0.0003 , desirability values of 0.986 and $R$-squared values of 0.950 . 
Response surface plot as a function of two variables at a time and holding all other variables at centre levels were more powerful tool for understanding the main and interaction effects. Therefore, the response surface and contour curves were plotted to understand the interaction of variables and to determine the optimum level of each variable for maximum response. The $\mathrm{pH}$ of the solution increased from 2 to 12 while the per cent reduction of BOD and COD increased (Fig. 5a). This might be due to the fact that at higher $\mathrm{pH}$, the functional groups of chitosan gets dissociated as their dissociation constants, thereby taking part in the surface complexation (Da-Silva-Alves et al., 2021). On the other side, the initial BOD concentration increased the per cent reduction of $B O D$ and $C O D$ showed a decreasing trend due to adsorption of more organic substances on the surface of the adsorbent. Thus distribution coefficient decreased limiting the number of absorption sites available for adsorption at a higher initial concentration of BOD and COD (Anjum et al., 2019).

The per cent reduction of $\mathrm{BOD}$ and $\mathrm{COD}$ increased with the increasing $\mathrm{CZnO}$ dosage. It may be presumed that, the availability of active sites on the $\mathrm{CZnO}$ nanoadsorbent increased at higher dosages. On the other side, the per cent reduction of $\mathrm{BOD}$ and COD decreased with the increasing pH (Fig. 5b). This may be due to the potential binding sites of chitosan containing amine and hydroxyl groups decreased at higher $\mathrm{pH}$ (Thirugnanasambandham and Sivakumar, 2015). The effect of contact time increased from 20 to $100 \mathrm{~min}$, the per cent reduction of $\mathrm{BOD}$ and $\mathrm{COD}$ increased significantly due to abundant availability of binding sites on the surface of $\mathrm{CZnO}$ at a prolonged time (Thirugnanasambandham and Ganesamoorthy, 2019). The perusal of data (Fig. $5 \mathrm{c}$ ) revealed that as $\mathrm{CZnO}$ dosage increased from 0.50 to $2 \mathrm{mg} \mathrm{l}^{-1}$, the per cent reduction of BOD and COD increased. To predict the BOD and $C O D$ adsorption behavior on $\mathrm{CZnO}$ nanoadsorbent, the $\mathrm{pH}$, initial concentration, contact time and adsorbent dosages were used as input variables and the $\% \mathrm{R}_{\text {воD }}$ and $\% \mathrm{R}_{\text {СоD }}$ were used as a target. The ranges of inputoutput variables for each system are given in Table 4 . The multilayer perceptron (MLP) was trained, validated and tested with $70 \%, 15 \%$ and $15 \%$ of experimental data, respectively.

The possibility of over-training was a problem in the ANN and can be overcome by proper selection of the number of neurons in the hidden layer. The performance of the network in training phase increased with increasing the number of neurons. At the same time, the performance of the network in testing data phase lead to optimum value at an optimal number of hidden neurons (Arismendy et al., 2020). In the present study, 4-layer feed forward back propagation neural network (4-3-1) was designed by changing the four process variables of batch adsorption experiments. The results were evaluated on the basis of $\% R_{B O D}$ and $\% R_{C O D}$. MLP consisted of one input layer associated with four nodes, one hidden layer associated with four hidden nodes and one output layer with one output node value. All these neurons and nodes were coupled with different weights and bias. A multilayer feed forward back propagation neural network was used with a hyperbolic tangent sigmoid (tansig) as a transfer function at a learning rate of 0.1 and momentum rate of 0.5 and 21 epochs. The ANN architecture was trained using a stopping criterion as 1000 iterations (Yadav et al., 2018).

Comparative results of BBD and ANN models showed that, the BBD model was larger than the ANN model. Linear regression analysis was carried out between the response values predicted by ANN and BBD models with their corresponding experimental values as shown in Fig. 6 (a-b). ANN model predictions available is much closer to the line of perfect prediction than the BBD model. Thus, ANN model showed a significantly higher generalization capacity than the BBD model. This higher predictive accuracy of ANN model can be attributed to its universal ability to approximate the nonlinearity of the system whereas the BBD is restricted to a second-order polynomial. Generation of ANN model requires a large number of iterative calculations whereas BBD is only a single step calculation. ANN model may require a high computational time and it was more costly than an BBD model (Sen et al., 2018).

In conclusion, the impact of operational parameters on the efficiency of adsorption process was carefully investigated by $B B D$ and ANN models. The optimal conditions obtained from BBD in the presences of $\mathrm{CZnO}$ nanoadsorbent for $\% \mathrm{R}_{\mathrm{BOD}}$ and $\% \mathrm{R}_{\mathrm{COD}}$ was found at 100 and $200 \mathrm{mg} \mathrm{I}^{-1}$ of initial BOD and COD concentration, $1.25 \mathrm{mg} \mathrm{l}^{-1}$ of adsorbent dosage, 7.0 and $2.0 \mathrm{of} \mathrm{pH}$, 100 and 60 min of contact time. The results of ANN model indicate that it is a highly robust statistical tool that accurately estimates dependent variables when compared with RSM.

\section{Acknowledgment}

The authors acknowledge their heartfelt gratitude to the Department of Science and Technology, Scheme for Young Scientist and Technologists (SYST) [SP/YO/2019/1583 (G)] New Delhi for the financial support extended for conducting this research work.

\section{Add-on Information}

Authors' contribution: B.L. Dinesha: Conceptualization, investigation, original draft preparation, conceived and designed the experiments; S. Hiregoudar: Project administration, funding acquisition, review and editing; U. Nodoni: Methodology, formal analysis, supervision, review and editing; K.T. Ramappa: Data analysis and discussion, revision of manuscript; A.T. Dandekar: Provided laboratory facility for analysis of BOD and COD; M.V. Ravi: Assisted in proof reading of manuscript; K.B. Sankalpa: Helped in BBD and ANN modeling, model validation, review and editing.

Research content: The research content of manuscript is original and has not been published elsewhere.

\section{Ethical approval: NotApplicable}

Conflict of interest: The authors declare that there is no conflict of interest. 
Data from other sources: NotApplicable

Consent to publish: All authors agree to publish the paper Journal of Environmental Biology.

\section{References}

Anjum, M., R. Miandad, M. Waqas, F. Gehany and M.A. Barakat: Remediation of wastewater using various nano-materials. Arab. J. Chem., 12, 4897-4919 (2019).

AOAC: Association of Official Analytical Chemists. $1^{\text {st }}$ action, Method 973.44 and $973.46 .16^{\text {th }}$ Edn, USA https://www.fda.gov/files/ food/published/Best-Practices-in-Microbiological-Methodology$\% 28$ Final-Report-and-Executive-Summaries-from-the-AOACInternational-Presidential-Task-Force\%29-Full-Document\%28PDF--3.6MB\%29. pdf(2006).

Arismendy, L., C. Cardenas, D. Gomez, A. Maturana, R. Mejia and C.G. Quintero: Intelligent system for the predictive analysis of an industrial wastewater treatment process. Sustainability, 12, 1-19 (2020).

Arora, S., A.K. Chopra, N. Joshi and G. Prasad: Physico-chemical and bacteriological characteristics of Aachal dairy mill effluent and its effects on seed germination of some agricultural crops. Nat. Environ. Pollut. Technol., 4, 441-444 (2005).

Bora, T. and J. Dutta: Applications of nanotechnology in wastewater treatment: A review. J. Nanosci. Nanotechnol., 14, 613-626 (2014)

Da-Silva-Alves, D.C., B. Healy, L.A. De-Almeida-Pinto, T.R. Sant-AnnaCadaval-Jr and C.B. Breslin: Recent developments in chitosanbased adsorbents for the removal of pollutants from aqueous environments. Molecules, 26, 1-45 (2021).

Dehaghi, S.M., B. Rahmanifar, A.M. Moradi and P.A. Azar: Removal of permerthrin pesticide from water by chitosan zinc oxide nanoparticles composite as an adsorbent. J. Soudi Chem. Soc., 18, 348-355 (2014).

Dinesha, B. L., H, Sharanagouda, N, Udaykumar., K.T. Ramappa, A.T. Dandekar and M.V. Ravi: Modelling and optimization of chitosan anchored titanium dioxide nano-adsorbent for dairy industry effluent treatment. ActaAlimen., 2, 1-11 (2021a).

Dinesha, B.L., H, Sharanagouda, N. Udaykumar., K.T. Ramappa, A.T. Dandekar and M.V. Ravi: Comparison of chitosan based nanoadsorbents for dairy industry wastewater treatment through response surface methodology and artificial neural network models. Water Sci. Technol., 35, 1-14 (2021b).

Dinesha, B.L., H. Sharanagouda, N. Udaykumar, C.T. Ramachandra and A.T. Dandekar. Removal of pollutants from water/wastewater using nano-adsorbents: A potential pollution mitigation. Int. J. Curr. Microb. Applied Sci., 6, 4868-4872 (2017).

Jha, P., E.B.G. Kana and S. Schmidt: Can artificial neural network and response surface methodology reliably predict hydrogen production and COD removal in an UASB bioreactor. Int. J. Hydrog. Energy, 42, 18875-18883 (2017).

Karimi, F., S. Rafiee, A. Taheri-Garavan and A.N. Karimi: Optimization of an air drying process for Artemisia absinthium leaves using response surface and artificial neural network models. J. Taiwan Inst. Chem. Eng., 43, 29-39 (2012).

Maran, J.P., V, Sivakumar, R. Sridhar and K. Thirugnanasambandham: Preparation and properties of plasticized chitosan starch cast film. Carbohydr. Polym., 92, 133-139 (2013).

Oladipo, A.A., O.J. Adeleye, A.S. Oladipoc and A.O. Aleshinloye:
Bioderived $\mathrm{MgO}$ nanopowders for $\mathrm{BOD}$ and $\mathrm{COD}$ reduction from tannery wastewater. J. Water Proc. Eng., 16, 142-148 (2017).

Pandiselvam, R., R. Kaavya, Y. Jayanath, K. Veenuttranon, P. Lueprasitsakul, V. Divya and S.V. Ramesh: Ozone as a novel emerging technology for the dissipation of pesticide residues in foods-a review. Trends Food Sci. Technol., 97, 38-54 (2020).

Pathak, U., P.P. Das, Banerjee and S. Datta: Treatment of wastewater from a dairy industry using rice husk as adsorbent: Treatment efficiency, isotherm, thermodynamics and kinetics modeling. $\mathrm{J}$. Thermodyn., 1, 127-138 (2016).

Preethi, S., K. Arana, M. Nithyasri, P. Kishore, K. Deepika, R. Ranjithkumar, V. Bhuvaneshwari and D. Bharathi: Synthesis and characterization of chitosan/zinc oxide nanocomposite for antibacterial activity onto cotton fabrics and dye degradation applications. Int. J. Biol. Macromol., 164, 2779-2787 (2020).

Qasim, W. and A.V. Mane: Characterization and treatment of selected food industrial effluents by coagulation and adsorption techniques. WaterResour. Ind., 4, 1-19 (2013).

Raut, A.V., R.K. Satvekar, S.S. Rohiwal, A.P. Tiwari, A. Gnanamani and S. Pushpavanam: In-vitro biocompatibility and antimicrobial activity of chitin monomer obtain from hollow fiber membrane. Des. Mono. Polym., 19, 445-455 (2016).

Sen, S., S. Nandi and S. Dutta: Application of RSM and ANN for optimization and modeling of biosorption of chromium(VI) using cyanobacterial biomass. Appl. Water Sci., 8, 1-12 (2018).

Srikanth, V., G.K. Rajesh, A. Kothakota, R. Pandiselvam, N. Sagarika, M.R. Manikantan and K.P. Sudheer: Modeling and optimization of developed cocoa beans extractor parameters using box behnken design and artificial neural network. Comput. Electron. Agric., 177, 105-715(2020).

Stoller, M., M.J.O. Pulido and O. Sacco: Optimized design of wastewater stream treatment processes by membrane technologies. Chem. Eng. Trans., 47, 391-396 (2016)

The, C.Y., T.Y. Wu and J.C. Juan: Optimization of agroindustrial wastewater treatment using unmodified rice starch as a natural coagulant. Ind. Crops Prod., 56, 17-26 (2014).

Thirugnanasambandham, K. and R. Ganesamoorthy: Dual treatment of milk processing industry wastewater using electro fenton process followed by anaerobic treatment. Int. J. Chem. Reactor Eng., 74, 110 (2019).

Thirugnanasambandham, K. and V. Sivakumar: Modeling and optimization of treatment of milk industry wastewater using chitosan zinc oxide nanocomposite. J. Desalin. Water Treat., 57, 205-223 (2015).

Thirugnanasambandham, K., V, Sivakumar and J.P. Maran: Treatment of egg processing industry effluent using chitosan as an adsorbent. $J$. Serbian Chem. Soc., 79, 743-757 (2014).

Thirumavalavan, M., K.L. Huang and J.F. Lee: Preparation and morphology studies of nano zinc oxide obtained using native and modified chitosans. Materials, 6, 4198-4212 (2013).

Wardana, A.A., F. Tanaka and F. Tanaka: Surface microstructure of nanocomposite from chitosan loaded with $\mathrm{ZnO}$ nanoparticle by automic force microscopy. Kye Eng. Mater., 862, 83-87 (2020).

Yadav, A.M., R.C. Chaurasia, N. Suresh and P. Gajbhiye: Application of artificial neural networks and response surface methodology approaches for the prediction of oil agglomeration process. Fuel, 22, 826-836 (2018)

Youssefi, S., Z.E. Djomeh and S.M. Mousavi: Comparison of artificial neural network (ANN) and response surface methodology (RSM) in the prediction of quality parameters of spray dried pomegranate juice. Drying Technol., 27, 910-917 (2013). 